\title{
Erratum to: Experimental Study of the Fatigue Stiffness Degradation for the Carbon Fiber Reinforced Plastic at Variable Temperature
}

\author{
A. A. Fedotov ${ }^{a, *}$ and A. V. Tsipenko ${ }^{a}$ \\ ${ }^{a}$ Moscow Aviation Institute (National Research University), Volokolamskoe shosse 4, Moscow, 125993 Russia \\ *e-mail: alexey.a.fedotov@inbox.ru \\ Received September 3, 2019; in final form, September, 5, 2019
}

DOI: $10.3103 /$ S1068799819030255

The name of the second author of the article should be read as A.V. Tsipenko.

The original article can be found online at https://doi.org/10.3103/S1068799819010033. 